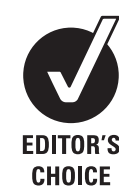

${ }^{1}$ Medical Education Research Group, Durham University, Durham, UK

${ }^{2}$ Department of Anaesthesia, Newcastle upon Tyne NHS Foundation Trust, Newcastle upon Tyne, UK

${ }^{3}$ Tees Esk and Wear Valleys NHS Foundation Trust, Kaizen Promotion Office, Lanchester Road Hospital, Durham, UK

\section{Correspondence to}

Dr Gill Morrow, Senior Research Associate, Medical Education Research Group, Durham University, Burdon House, Leazes Road, Durham DH1 1TA, UK;

g.m.morrow@durham.ac.uk

Received 20 September 2011 Accepted 4 June 2012 Published Online First 5 July 2012

\title{
Does specialty training prepare doctors for senior roles? A questionnaire study of new UK consultants
}

\author{
Gill Morrow, ${ }^{1}$ Bryan Burford, ${ }^{1}$ Nancy Redfern, ${ }^{2}$ Ruth Briel, ${ }^{3}$ Jan Illing ${ }^{1}$
}

\begin{abstract}
Aim To measure new consultants' perceptions of their preparedness for different clinical and non-clinical aspects of the role of consultant.

Design A cross-specialty questionnaire was developed and validated, containing items asking how well specialty training had prepared respondents for the role of consultant in a number of clinical and non-clinical areas. Responses were on a five-point Likert scale with a 'Not relevant/no opinion' box, and one free text section. Analysis was carried out on 10 scales derived from the questionnaire items through exploratory factor analysis. Participants Consultants who had completed their specialty training in the north of England between 2004 and 2009 and had held a substantive consultant post in the region for $<5$ years were sent questionnaires in late 2009.
\end{abstract}

Results The effective response rate was 70.6\% (211/ 299). Ten factors reflecting areas including clinical skills, communication skills, team and resource management were identified. Overall, higher scores were observed on factors relating to 'providing care for individual patients' rather than 'having responsibility for the system of care'. The lowest scoring factors related to resource management and supervision, with mean scores falling below the scale midpoint. There were no significant differences between specialty groups, or on any demographic variables.

Conclusions A questionnaire to measure new consultants' perceptions of how well their specialty training had prepared them for practice was developed and validated. Findings were similar across specialties, suggesting that training programmes in all areas need to integrate higher-level management skills into their curricula, alongside the development of clinical expertise.

\section{INTRODUCTION}

The transition from trainee to senior grade doctor (specialist registrar to consultant, or resident to attending) is a challenging and stressful stage in a doctor's career. ${ }^{1-5}$ The consultant role in a modern healthcare setting involves greater responsibility in areas such as service planning, staff management, managing resources and healthcare governance, and doctors have reported feeling less prepared for these non-clinical aspects of the role than for the clinical aspects. ${ }^{4-10}$ Recognition that doctors have roles beyond clinical care, for which they may not be prepared by curricula, is not new, ${ }^{11}{ }^{12}$ but is an area of concern which has still not been fully resolved.

The involvement of doctors in the organisation of services is seen as important if progress is to be made in providing high-quality care. ${ }^{13} 14$ A stronger leadership role for doctors in key management practices has been linked to better healthcare and higher productivity, ${ }^{15}$ and lack of involvement of doctors in the management and leadership of an organisation can be linked to failures in care. ${ }^{16}$ Key factors identified in these failures include inadequate medical leadership, poor communication, disempowerment of staff and patients and a disconnection between staff and managers. ${ }^{17}$ The complex nature of healthcare organisations as professional bureaucracies requires leadership at different levels, not just at the top. ${ }^{18}$

Internationally, it is recognised that the responsibilities of doctors are changing, with increased team-working and accountability for a system that delivers healthcare to the population, as well as for care of the individual patient. ${ }^{18} 19$ For example, in the UK, since the early 1980s doctors have been required to become more accountable for making decisions on resource allocation. These changes run counter to the cultural values usually ascribed to doctors, that is, a strong sense of clinical autonomy and accountability to individual patients, ${ }^{20}$ and may have created tensions between doctors and managers. ${ }^{18} 21$ The experiences of clinicians who have made the transition to management roles indicate an essential difference in professional identity, ${ }^{22}$ and the professional status of physicians comprises values and norms different to the economic goals of hospitals. ${ }^{23}$

The first qualitative phase of the current study found that trainers, specialist trainees and curricula do not seem to fully acknowledge the diversity and complexity of the role of the modern medical consultant. ${ }^{6}$ This earlier work is outlined in box 1 .

The second phase of the work sought to further explore whether UK specialty training prepares consultants fully for the new roles they will play in a modern healthcare setting. The study was carried out in one region of the UK-the Northern Deanery (deaneries are organisations within the structure of the UK National Health Service (NHS) responsible for postgraduate medical and dental training at regional level. The Northern Deanery covers the northeast of England and parts of Cumbria to the west). Specialty curricula are set at a national level, although delivery may vary at a local level.

The aim was to establish the perceived preparedness, for a number of aspects of practice, of a larger group of new consultants working in a range of specialties. A questionnaire was used as it allows data to be gathered from a larger sample. The objectives of this phase of the study were:

- To develop and validate a measure of new consultants' perceptions of their preparedness for practice. 


\section{Box 1 Summary of qualitative study}

The aim of the qualitative study was to determine the extent to which specialty training provides doctors with the skills they require when they become consultants.

Face-to-face interviews with 32 final year specialty trainees and 20 telephone interviews with newly appointed consultants explored expectations of the consultant role and their own preparedness. Issues were triangulated with telephone interviews with 12 medical managers who had an overview of new consultants' performance.

There was agreement that clinical work was the area with the highest perception and observation of preparedness, with some adjustment needed to increasing responsibility, including for decision making, prioritisation and delegation. Understanding of, and adjustment to, a more organisational and managerial role was needed, in particular, with regard to designing, developing and changing services. There was anticipation of poor preparedness for people management, for example, addressing poor performance, and new consultants felt poorly prepared for providing feedback to trainees. Other areas of concern included dealing with complaints, time management and job planning. Some specialty trainees lacked full appreciation of all aspects of the consultant role, and exposure to the full role varied, for example, opportunities to attend management meetings and exposure to complaints procedures.

- To compare preparedness for different aspects of the role.

- To compare the preparedness of different subgroups through implementation of this tool.

\section{METHOD}

\section{Questionnaire development}

A cross-specialty questionnaire was developed from themes generated from the qualitative work, from earlier literature and through consultation with experts. The items were designed to cover six areas which were identified as important: clinical skills, communication, teaching and supervision, management and team-working, healthcare governance and general professional aspects of the role of consultant. The aim of the questionnaire was to produce aggregated scales to measure preparedness for different areas of practice.

The questionnaire was pre-tested with an opportunistic sample of 12 newly appointed consultants from a range of specialties working in the Northern Deanery. This resulted in changes to the wording of five questions and the addition of three more questions. A revised version of the questionnaire was then piloted by post with a larger sample of 30 newly appointed consultants selected randomly from the full sample. As this resulted in no further changes to the questionnaire these responses were included in the final analysis.

The final version of the questionnaire comprised 68 items which asked respondents how well their specialty training had prepared them for the role of consultant in each of the six areas. Response to all items was on a five-point Likert scale with anchors at each end only-from 1 ('not at all well') to 5 ('extremely well'). A not relevant/no opinion box was also included. A free text section enabled respondents to provide additional comments about their specialty training or recommendations for improvement.

\section{Participants}

The questionnaire was distributed by post to 323 consultants who had completed their specialty training in the Northern Deanery between 2004 and 2009, and had been working in a substantive consultant post in the region for less than five years. Participants were recruited from a consultant lists matched against Northern Deanery databases for date of completion of training. Two screening questions were included in the questionnaire to ensure that the responses came from the target sample (ie, location of specialty training and length of time in post). The questionnaire was distributed in late 2009 and was followed up by two reminders, two weeks and four weeks after the initial distribution. The questionnaires were returned directly to the researchers and had no identification code, thus ensuring anonymity of responses.

\section{Data analysis}

\section{Validation analysis}

To ensure the construct validity of the questionnaire, the proportions of missing data per items were examined (high levels of missing data suggesting that an item is inappropriate or unclear), and an exploratory factor analysis conducted to establish how items associated with different components of practice relate to each other. Reliability statistics (Cronbach's $\alpha$ ) were calculated for the resultant scales. Because the questionnaire is measuring subjective preparedness, and there are no adequate indicators of actual preparedness to indicate actual preparedness, no analysis of predictive or concurrent validity is possible.

\section{Exploratory analysis}

Descriptive statistics for the different factors were examined to identify areas of high and low perceived preparedness. Comparisons between specialty groups, male and female doctors, and those qualified in the UK and elsewhere were conducted using nonparametric significance tests.

\section{RESULTS}

Of the 323 questionnaires distributed, 24 were returned undelivered due to incorrect addresses. Two hundred and eleven questionnaires were completed $(65.3 \%$ of the total), giving an effective response rate of $70.6 \%$.

\section{Demographics}

The demographic breakdown of the sample is given in table 1. The majority of responses were from men $(62.6 \%, n=132$; $37.4 \%, \mathrm{n}=79$ from women), and most were in the 35-44 age group $(81.5 \%, \mathrm{n}=172)$. The majority described themselves as white $(65.8 \%, \mathrm{n}=139$, of whom 123 described themselves as 'white British'). Only one reported that they had a disability.

Respondents had completed their basic medical education in 14 countries, most in the UK $(68.7 \%, n=145)$, followed by India $(19 \%, n=40)$. To consider any effects of place of undergraduate study, the reported countries were re-coded to compare UK $(n=145)$, European Economic Area $(n=13)$ and other international graduates $(n=47)$.

While respondents were selected on the basis of training in the Northern Deanery, $14.7 \% \quad(n=31)$ reported they had also undertaken some training in another deanery. Several had completed at least some of their specialty training in part-time hours $(15.7 \%, n=33)$, and $29.3 \% \quad(n=60)$ had completed a doctorate $(\mathrm{MD}$ or $\mathrm{PhD})$ during their training. Respondents had been in a substantive consultant post for between one month and five years (mean=30.6 months). 
Table 1 Sample demographics

\begin{tabular}{lcc}
\hline & Number & Per cent \\
(of 211 responses)
\end{tabular}

\section{Representation of different specialties}

The questionnaire asked respondents to provide their clinical specialty as a free text response. Responses ranged from the general (eg, medicine, surgery) to specific subspecialties (eg, neonatology, hepatology, neuroradiology). To allow comparisons between groups, these were re-coded into broad specialty groups providing sufficient numbers for statistical comparison. These groupings should meaningfully aggregate different training experiences. Frequencies of different specialty groups, and their gender profiles, are given in table 2.

\section{Validation analysis}

Use of scale and missing data

There were no missing data arising from items not being completed, and low numbers of 'not relevant' responses (across all items, for all respondents, there were 396 'not relevant' responses, $<2 \%$ of the total). Table 3 lists those items for which more than $5 \%$ of responses were 'not relevant'. Together, these account for $61 \%$ of all such responses. Within these, there is over-representation of lab medicine (15\% of responses compared with $4 \%$ of sample), and radiology (19\% compared with $7 \%$ ), and under-representation of medicine and surgery (respectively, $18 \%$ of responses and $33 \%$ of sample, and $3 \%$ of responses and $16 \%$ of sample). This suggests that the items are less likely to be relevant to those doctors who do not have constant patient contact.

These figures indicate content validity, as items are felt to be relevant to the majority of respondents. The majority of the 68 items showed use of both ends of the scale, indicating discriminant validity. While there was a negative skew with some items having few ratings at 1 or 2 (indicating preparedness), this is not considered a problem in a sample who have completed training.

\section{Factor analysis}

Principal components analysis (PCA) was carried out in SPSS V.17. 'Not applicable' responses were treated as missing data in this analysis.

An initial analysis identified a low Kaiser-Mayer-Olkin statistics of sampling adequacy (KMO) of 0.677 . Examination of $\mathrm{KMOs}$ for individual items identified one (for 'Clin constructing procedures') as particularly low at 0.366 . Repeating the analysis with this item omitted increased the overall $\mathrm{KMO}$ to 0.846, defined as 'good' according to Field, ${ }^{24}$ but there were multiple cross-loadings and spurious factors consisting of just one item.

Elimination of cross-loading items resulted in a 10 factor solution (eigenvalues $>1$ ), with a $\mathrm{KMO}$ of 0.867 , and communalities ranging from 0.607 to 0.888 , meaning that between $61 \%$ and $89 \%$ of the variance in these items is explained by the retained factors. No cross-loadings with differences of $<0.3$ were present in the final factor structure. The $\mathrm{KMO}$ and communality statistics are taken to be indicative of a dataset appropriate for factor analysis, and are preferred as an indicator of appropriateness, rather than the ratio of participants to items. ${ }^{25}$

The solution is summarised in table 4, which gives the items with a loading $>0.40$ (ie, accounting for more than $16 \%$ of

Table 2 Frequencies of specialty groups, and gender profiles

\begin{tabular}{|c|c|c|c|c|c|c|}
\hline & Frequency & Per cent of sample & n Female & n Male & $\%$ Female & $\%$ Male \\
\hline Medicine* & 69 & 33.0 & 26 & 43 & 37.7 & 62.3 \\
\hline Surgery† & 34 & 16.3 & 4 & 30 & 11.8 & 88.2 \\
\hline Psychiatry/mental health & 32 & 15.3 & 15 & 17 & 46.9 & 53.1 \\
\hline Anaesthetics & 25 & 12.0 & 8 & 17 & 32.0 & 68.0 \\
\hline Radiology & 15 & 7.2 & 5 & 10 & 33.3 & 66.7 \\
\hline Paediatrics & 14 & 6.7 & 9 & 5 & 64.3 & 35.7 \\
\hline Obstetrics and gynaecology & 12 & 5.7 & 5 & 7 & 41.7 & 58.3 \\
\hline Lab medicine & 8 & 3.8 & 6 & 2 & 75.0 & 25.0 \\
\hline Total & 211 & 100.0 & & & 37.0 & 62.1 \\
\hline
\end{tabular}

*Including emergency medicine, acute medicine, care of the elderly, dermatology, diabetes and endocrinology, gastroenterology, palliative medicine, renal medicine, respiratory medicine, rheumatology.

†Including general surgery, orthopaedics, plastic surgery, ENT. 
Table 3 Items which had more than $5 \%$ of responses 'not relevant'

\begin{tabular}{|c|c|c|c|}
\hline Item & $\begin{array}{l}\text { Number of } \\
\text { 'not relevant' } \\
\text { responses }\end{array}$ & $\begin{array}{l}\% \text { Of } \\
\text { participants }\end{array}$ & $\begin{array}{l}\% \text { From lab } \\
\text { or radiology } \\
(5.5 \% \text { of sample })\end{array}$ \\
\hline $\begin{array}{l}\text { Constructing and supervising } \\
\text { procedure lists, eg, operating } \\
\text { lists, bronchoscopy lists }\end{array}$ & 82 & 39 & 13 \\
\hline $\begin{array}{l}\text { Leading a post-take ward } \\
\text { round }\end{array}$ & 71 & 34 & 30 \\
\hline $\begin{array}{l}\text { Organising and managing } \\
\text { clinics }\end{array}$ & 39 & 19 & 41 \\
\hline $\begin{array}{l}\text { Managing long-term } \\
\text { conditions }\end{array}$ & 22 & 10 & 36 \\
\hline $\begin{array}{l}\text { Negotiating a complex } \\
\text { referral to another specialty }\end{array}$ & 15 & 7 & 80 \\
\hline $\begin{array}{l}\text { Involving patients or the } \\
\text { public in evaluating or } \\
\text { changing services }\end{array}$ & 12 & 6 & 25 \\
\hline Total & 241 & & \\
\hline
\end{tabular}

variance of the factor), and the variance explained for each factor. The solution explains $79.7 \%$ of the total variance.

\section{Descriptive statistics}

Table 5 presents the descriptive statistics for the factors as calculated from the simple aggregation of the items shown in table 4. Each aggregated scale shows internal consistency, with Cronbach's $\alpha$ for each factor $>0.8$. As eight of the 10 factors were scored at or above the midpoint, the results tended towards preparedness, although several were nearer the neutral midpoint than the upper end of the scale. Two factors had means (and $95 \%$ CIs) below the midpoint. While not at the bottom of the scale, these factors indicate relatively low preparedness.

Overall, the factors with means at the upper end of the scale were those which may be seen as related to 'being a clinician' rather than 'being a manager'; that is, the skills which are part of the standard course of practice as a trainee, compared with those which are only part of a consultant's role.

At the lower end of the scale, the factors relating to resource management and supervision had mean scores below the midpoint. Time management and 'supporting activities' were also quite low. Interestingly, teaching is rated relatively high compared with supervision, suggesting it is the management, and dealing with concerns about poor performance, rather than strictly the educational component, for which the respondents feel under-prepared.

\section{Differences between subgroups}

Further analysis compared the factor scores (calculated by the regression method, so taking account of the weighted contribution of each item) between different subgroups: specialty group, gender, age, country of primary medical qualification, whether trainees had trained full or part-time, or whether they had completed a doctorate. Nonparametric methods were used because of the differences in sample sizes. The Bonferroni correction for multiple comparisons was applied to reduce the likelihood of a type I error (false positive) - this moves the threshold for statistical significance to reflect the 'family' of tests being carried out, in this case, the 10 factors. Results were, therefore, considered to be statistically significant if $p<0.005$ (rather than 0.05). No results were significant at this level, and the conclusion, therefore, is that the factor scores are consistent across the sample subgroups.

Respondents had been in a substantive consultant post for between one month and five years (mean=30.6 months). A negative correlation between this variable and the 'Teaching' factor was statistically significant, albeit with a small effect size $(\rho=-0.259, p<0.01)$. This suggests that the respondents felt less prepared for teaching the longer they had been in their consultant post. No other correlations were statistically significant (all other $\rho<0.2$ ).

\section{Free text responses}

The free text responses in box 2 illustrate how preparedness for some of these factors is described by some respondents, provide some suggested improvements to training, and give an indication of some trainee attitudes towards training.

\section{DISCUSSION}

This paper has presented the development and validation of a questionnaire to assess new consultants' perceptions of the degree to which their specialty training prepared them for work as a consultant. Ten areas of practice were derived from a factor analysis, with a trend towards greater preparedness for more obviously clinical tasks, and less preparedness for management tasks. No differences were found between specialty or demographic groups.

These findings support those of earlier research in individual specialties, regarding perceptions of higher preparedness for clinical than non-clinical aspects of the consultant role. ${ }^{4-10}$ In this study, the areas in which respondents felt more prepared may be seen as those relating to 'providing care for individual patients' rather than 'having responsibility for the system of care'.

Lack of preparedness for some aspects of a senior management role (such as resource management-related to finance and service development) may be expected to an extent as there will be fewer opportunities to practise those aspects in training. However, even in some elements of practice that have traditionally been part of the consultant role (eg, time management and supervision), new consultants did not rate their preparedness highly. The results do not necessarily mean that the new consultants are unprepared or lack competence, and the midpoint of the scale around which the lower means clustered was neutral. However, if trainees complete their training even feeling underprepared for some, even minor, aspects of the job they have been trained for, there may be concerns about elements of their training.

The strength of the current study is its cross-specialty scope, large sample size and a high response rate. Most other studies on the transition from specialist trainee to medical specialist have been limited by the fact that they report on transitions in highly specialised medical disciplines, which hampers their transferability to a broader range of disciplines. ${ }^{26} \mathrm{~A}$ limitation of this study is that it provides only the perspective of newly appointed consultants themselves. However, while perception of preparedness may not be indicative of actual ability, it does have a potential effect on the doctors' confidence to take on, or even avoid, certain aspects of the role. A further possible limitation is that the study was conducted in one area of the UK only. In the UK, curricula are nationally set through Royal Colleges and the GMC; while there may be national differences, there is no reason to suggest these may be greater than local differences. However, generalisation to other countries and other healthcare systems cannot be assumed. Since these respondents started their medical training, changes have been made to curricula at undergraduate and postgraduate levels, and it may be that repeating this study in a few years would find greater preparedness for managerial responsibility. 
Table 4 Factor labels, items loading $>0.40$ and variance explained

\begin{tabular}{|c|c|c|c|}
\hline $\begin{array}{l}\text { Factor } \\
\text { number }\end{array}$ & Factor label & Items loading $>0.40$ & $\begin{array}{l}\text { Variance } \\
\text { explained }\end{array}$ \\
\hline 1 & Supervision & $\begin{array}{l}\text { The role of the clinical supervisor } \\
\text { The role of the educational supervisor } \\
\text { Providing feedback to trainees } \\
\text { Raising concerns about a doctor's performance } \\
\text { Managing concerns about a doctor's performance } \\
\text { Supporting a poorly performing doctor }\end{array}$ & 14.2 \\
\hline 2 & $\begin{array}{l}\text { Resource } \\
\text { management }\end{array}$ & $\begin{array}{l}\text { Designing new services } \\
\text { Managing resources effectively } \\
\text { Making decisions about allocating resources } \\
\text { Inputting into a business plan } \\
\text { Managing NHS targets } \\
\text { Understanding the structure, financing and operation of the NHS } \\
\text { Changing the way a service is run }\end{array}$ & 13.6 \\
\hline 3 & Clinical interactions & $\begin{array}{l}\text { Presenting clinical cases to colleagues } \\
\text { Communicating results of investigations to colleagues } \\
\text { Communicating with colleagues in the wider health community } \\
\text { Dealing with administrative tasks, eg, clinical letter writing } \\
\text { Leading a post-take ward round } \\
\text { Negotiating a complex referral to another specialty }\end{array}$ & 10.4 \\
\hline 4 & $\begin{array}{l}\text { Teamwork/person } \\
\text { management }\end{array}$ & $\begin{array}{l}\text { Delegating to team members } \\
\text { Leading a team } \\
\text { Managing change within a team } \\
\text { Managing conflict within a team }\end{array}$ & 6.6 \\
\hline 5 & Time management & $\begin{array}{l}\text { Time management } \\
\text { Prioritising clinical and non-clinical work } \\
\text { Taking on an appropriate amount of new opportunities as a new consultant } \\
\text { Achieving good work/life balance }\end{array}$ & 6.5 \\
\hline 6 & Audit & $\begin{array}{l}\text { Carrying out an audit } \\
\text { Completing an audit cycle leading to a change in practice } \\
\text { Supervising audit }\end{array}$ & 6.2 \\
\hline 7 & Clinical skills & $\begin{array}{l}\text { Selecting appropriate investigations } \\
\text { Diagnostic skills } \\
\text { Interpreting results of investigations }\end{array}$ & 6.1 \\
\hline 8 & $\begin{array}{l}\text { Communication } \\
\text { skills }\end{array}$ & $\begin{array}{l}\text { Communicating with patients and relatives } \\
\text { Communicating with patients who you find challenging } \\
\text { Taking leadership when breaking bad news }\end{array}$ & 5.4 \\
\hline 9 & $\begin{array}{l}\text { Supporting } \\
\text { activities/skills }\end{array}$ & $\begin{array}{l}\text { Being involved in research } \\
\text { Use of IT for patient care } \\
\text { Use of IT for supporting professional activities (SPAs) }\end{array}$ & 5.4 \\
\hline 10 & Teaching & $\begin{array}{l}\text { Lecturing } \\
\text { Small group teaching } \\
\text { Demonstrating, explaining or teaching in the work setting }\end{array}$ & 5.3 \\
\hline
\end{tabular}

Internationally, many organisations and governments have recognised that doctors need a set of skills greater than those required to look after the health of individual patients. It has been identified that involving doctors in management and leadership is a crucial factor contributing to improvement in healthcare organisations, and there is a need to develop these skills. ${ }^{13-16} 182027$ This study, however, demonstrates that doctors in the UK's NHS, in all specialties, feel less prepared by their training for these broader aspects of the role. At the same time, policy changes ${ }^{28}$ and budgetary restrictions require clinicians to be involved in decisionmaking processes far more centrally.
While free text responses suggest that there are implications for trainees themselves, in terms of their prioritisation and proactiveness, the capacity to gain non-clinical skills needs to be seen as core by trainees and trainers alike, and the findings of this study clearly have implications for those responsible for medical training.

In the UK, the GMC has already responded to the changing nature of the role of doctors in healthcare in its regulatory standards, for example, by making explicit the role of 'Doctor as Leader' within its core statement of Good Medical Practice, ${ }^{29}$ setting out the wider responsibilities of doctors in draft guidance

Table 5 Un-weighted mean scores for items in table 3 (factors sorted in order of descending mean score)

\begin{tabular}{|c|c|c|c|c|c|c|c|}
\hline Factor number & Factor label & $\mathbf{N}$ & Minimum & Maximum & Mean & SD & $95 \% \mathrm{CI}$ \\
\hline 7 & Clinical skills & 211 & 2.67 & 5.00 & 4.53 & 0.50 & 4.46 to 4.60 \\
\hline 8 & Patient communication skills & 205 & 1.67 & 5.00 & 4.20 & 0.68 & 4.11 to 4.30 \\
\hline 3 & Clinical interactions & 211 & 2.33 & 5.00 & 4.09 & 0.60 & 4.01 to 4.17 \\
\hline 6 & Audit & 211 & 1.67 & 5.00 & 4.02 & 0.81 & 3.90 to 4.13 \\
\hline 10 & Teaching & 211 & 2.00 & 5.00 & 3.82 & 0.76 & 3.71 to 3.92 \\
\hline 4 & Team management & 211 & 1.00 & 5.00 & 3.47 & 0.76 & 3.36 to 3.57 \\
\hline 5 & Time management & 211 & 1.00 & 5.00 & 3.32 & 0.85 & 3.20 to 3.43 \\
\hline 9 & Supporting activities/skills & 209 & 1.00 & 5.00 & 3.28 & 0.96 & 3.15 to 3.41 \\
\hline 1 & Supervision & 210 & 1.00 & 5.00 & 2.69 & 0.88 & 2.57 to 2.81 \\
\hline 2 & Resource management & 211 & 1.00 & 5.00 & 2.27 & 0.87 & 2.15 to 2.39 \\
\hline
\end{tabular}




\section{Box 2 Illustrative free text responses}

\section{Experiences of training}

I think my clinical training in diagnostic and clinical management, both of patients and the resources of the NHS, has been excellent. I have felt that education in managing complaints/difficult patients and particularly problematic colleagues has been poor. In addition, the managerial aspects of putting together business plans, and the organisation of the NHS, are poorly covered. I had to attend extra courses to gain some knowledge in these areas. (CO10)

Training was good in day-to-day work management in (specialty) with good on-call experience. I feel training was lacking in some areas, such as dealing with complaints, setting up new services, business plans, etc. Apart from supervising junior trainees when I was a final year SpR, I did not feel that I was treated any different, and would have benefited from more involvement in managerial areas as far as possible. (CQ185)

The system of rotating around hospitals generally provided good and varied clinical training. However, it made it difficult to become involved in some of the non-clinical aspects of the job, particularly, designing new services, initiating/managing change, etc. (CO77)

\section{Suggested improvements to training}

A major weakness of the otherwise good training was the poor involvement in the business management side. Even in my final year, I was never invited or involved in any business meetings, it was more important for the SpR to keep up the service. I would suggest that SpRs should learn the business side of the NHS organisation as they go along, like they do with their teaching skills. I also suggest that SpRs should have more formal teaching in education, whether it is as a teacher or clinical supervisor. Also, the risk management issues and implications could be better taught. However, I had an excellent clinical training. (CO120)

As my consultant role evolves, I realise that my understanding of how the 'system' really works, and who I need to speak to, to make things happen, is not as good as I thought it was. The 'non' clinical managerial roles now seem to outweigh the clinical tasks on which I focused during training. These aspects of the role should be an earlier part of specialty training. (CO74)

Clear guidance on SPA/job planning would have been very helpful (eg, from BMA rep). Managing complaints: training needed. Managing poor performing juniors: need advice/training (CO93)

I think more specific time on day-to-day management of a service would help, that is, prioritising OP (outpatient) referrals, how to change/ set up a service, tying in service with targets, responding to complaints. Need more on NHS structure (national and local) earlier on rather than just in final year management course, which is good, but almost too new to take in at each stage (CQ190)

Encourage greater exposure to management meetings in the final 12 months of training (CO42)

All final and pre-final registrars need training in follow up of their own patients for a year with consultant supervision/support in outpatient setting. (CO26).

\section{Attitude towards training}

The most important aspect of specialty training in my view remains clinical, especially for specialties like surgery. If you can't operate you can't do the job! (CQ111).

In some areas, my negative choices may reflect a lack of personal motivation in seeking knowledge/experiences. I think these areas MUST be part of the trainee's curriculum. (CO79).

on Good Management Practice ${ }^{30}$ and issuing a new guidance document on leadership and management for all doctors. ${ }^{31}$ Elsewhere in the world, doctors are being encouraged to take on broader leadership roles. Denmark has been noted for its explicit aim to engage doctors in leadership roles and its efforts to provide training and support at postgraduate and consultant levels. ${ }^{32}$ In Canada, the physician manager role has been identified as one of the seven core competencies for specialist physicians (http://rcpsc.medical.org/canmeds/index.php). In the USA, it has been suggested that time away from direct clinical responsibilities is needed to allow for substantial engagement in other physician activities, such as management of the delivery of healthcare services, quality improvement initiatives, community work and advocacy. ${ }^{33}$ Leadership training at undergraduate level, however, seems to be less common internationally. ${ }^{32}$

In the UK, a five-domain Medical Leadership Competency Framework, along with a Medical Engagement Scale, has been designed to ensure that all medical students and doctors (hospital doctors and general practitioners) acquire competence in management and leadership and understand that this is integral to their role. ${ }^{34}$ The Medical Leadership Competency Framework has now been incorporated into undergraduate and postgraduate training.
Within the UK, Medical Royal Colleges are addressing this in different ways. For example, the Royal College of Psychiatrists is just about to produce a study Guide for Higher Trainees which uses the findings from this research to address deficits in training, by setting out opportunities for on-the-job learning in the hope that future consultants will be more prepared for the demands of their job.

Future research may be needed to ensure these educational interventions make a difference for future medical leaders.

\section{CONCLUSION}

This paper moves away from using the term management and/ or leadership, as these terms can have many definitions and lack specificity. Instead, it is suggested that one set of skills is required to look after individual patients and another set of skills and knowledge is required by doctors to ensure a healthcare organisation provides high-quality healthcare to all patients. While recognising these skills can overlap and be complementary, it is this second category in which doctors feel less confident and less well trained. There are, possibly, many reasons for this, which may include relatively low representation in the curriculum, timing or methods of assessment, and trainee attention and engagement. The similarity of findings 


\section{Main messages}

- New consultants feel less prepared by their training for elements of their work relating to the organisation of healthcare, rather than delivery of care to the individual patient.

- Findings were similar across specialties, suggesting that training programmes in all areas need to integrate higher-level management skills into their curricula alongside the development of clinical expertise.

- Specialty training programmes should review their coverage of areas including resource management, service development, supervision and dealing with poor performance.

\section{Current research questions}

- How can training programmes improve management skills without compromising clinical skills?

- To what extent do the medical profession, including specialty trainees, value management skills in training?

- How can training programmes reflect and respond to policy developments, such as changes in commissioning services?

\section{Key references}

- Brown J, Ryland I, Shaw N, et al. Working as a newly appointed consultant: a study into the transition from specialist registrar. Br J Hosp Med 2009;70:410-14.

- Westerman M, Teunissen PW, van der Vleuten CPM, et al. Understanding the transition from resident to attending physician: a transdisciplinary, qualitative study. Acad Med 2010;85:1914-19.

- Morrow G, Illing J, Burford B, et al. Are specialist registrars fully prepared for the role of consultant? Clin Teach 2009;6:87-90.

- Busari J0, Berkenbosch L, Brouns JW. Physicians as managers of health care delivery and the implications for postgraduate medical training: a literature review. Teach Learn Med 2011;23:186-96.

across specialties suggests that training programmes in all areas need to integrate management skills into their curricula alongside the development of the clinical expertise that is core to their consultant role. Particular attention may need to be given to the resource management and service development aspects of training, and also to supervision and handling poor performance. Further work will be required to explore the best methods of developing these skills and competencies for doctors.

Acknowledgements We would like to thank all the consultants who completed this questionnaire. We also thank Paul Crampton, Research Assistant, for support with data entry.

Contributors GM devised the questionnaire with contributions from all authors. BB and GM analysed and reported the results. All authors contributed to interpretation of the data and to earlier drafts and the final version of this paper.
Funding The work was carried out while GM, BB, Jl and NR were employed by the Northern Deanery. GM, BB and JI were employed to carry out independent research on behalf of the Deanery and NR acted as adviser to this piece of research.

Competing interests This work was carried out while GM, BB and $\mathrm{Jl}$ and NR were employed by the Northern Deanery. GM, BB and JI were funded to carry out independent research on behalf of the Deanery; NR acted as adviser to this piece of research; they declare no financial relationships with any organisations that might have an interest in the submitted work in the previous 3 years; no other relationships or activities that could appear to have influenced the submitted work. RB declares no support from any organisation for the submitted work; no financial relationships with any organisations that might have an interest in the submitted work in the previous 3 years; no other relationships or activities that could appear to have influenced the submitted work

Ethics approval This study received ethical approval from the NHS National Research Ethics Service (Sunderland Research Ethics Committee).

Provenance and peer review Not commissioned; externally peer reviewed.

\section{REFERENCES}

1. Brown J, Ryland I, Shaw N, et al. Working as a newly appointed consultant: a study into the transition from specialist registrar. Br J Hosp Med 2009;70:410-14.

2. Wilkie G, Raffaelli D. In at the deep end: making the transition from SpR to consultant. Adv Psychiatr Treat 2005;11:107-14.

3. Robinson R, Morreau J, Leighton $\mathrm{M}$, et al. New hospital consultant: surviving a difficult period. N Z Med J 2007;120. http://www.nzma.org.nz/journal/120-1259/ 2662/ (accessed 5 Jun 2011).

4. Westerman M, Teunissen PW, van der Vleuten CPM, et al. Understanding the transition from resident to attending physician: a transdisciplinary, qualitative study. Acad Med 2010;85:1914-19.

5. Benstead K. What is valuable for specialist registrars to learn in order to become good consultant clinical oncologists? Clin Oncol 2006;18:549-54.

6. Morrow G, Illing J, Burford B, et al. Are specialist registrars fully prepared for the role of consultant? Clin Teach 2009;6:87-90.

7. Higgins R, Gallen D, Whiteman S. Meeting the non-clinical education and training needs of new consultants. Postgrad Med J 2005;81:519-23.

8. Beckett M, Hulbert D, Brown R. The new consultant survey 2005. Emerg Med J 2006;23:461-3.

9. McKinstry B, Macnicol M, Elliot K, et al. The transition from learner to provider/ teacher: the learning needs of new orthopaedic consultants. BMC Med Educ 2005;5:17.

10. Berkenbosch L, Brouns JWM, Heyligers I, et al. How Dutch medical residents perceive their competency as manager in the revised postgraduate medical curriculum. Postgrad Med J 2011;87:680-7.

11. Berwick DM, Enthoven A, Bunker JP. Quality management in the NHS: the doctor's role-I. BMJ 1992;304:235-9.

12. Berwick DM, Enthoven A, Bunker JP. Quality management in the NHS: the doctor's role -I I. BMJ 1992:304:304-8.

13. General Medical Council. Management For Doctors. 2006. http://www.gmc-uk. org/guidance/ethical guidance/management for doctors.asp laccessed 5 Jun 2011).

14. Department of Health. High Quality Care For All. NHS Next Stage Review Final Report. 2008. http://www.dh.gov.uk/en/Publicationsandstatistics/Publications/ PublicationsPolicyAndGuidance/DH_085825 (accessed 5 Jun 2011).

15. Castro PJ, Dorgan SJ, Richardson B. A healthier health care system for the United Kingdom. McKinsey q 2008. http://www.mckinseyquarterly.com/ A_healthier_health_care_system_for_the_United_Kingdom_2101 laccessed $13 \mathrm{Ap}$ 2012).

16. Kennedy Report. The Report of the Public Inquiry into Children's Heart Surgery at the Bristol Royal Infirmary 1984-1995, Cm 5207 (1). Norwich: The Stationery Office, 2001.

17. The Mid Staffordshire NHS Foundation Trust Inquiry. Independent inquiry into care provided by mid Staffordshire NHS Foundation Trust January 2005 - March 2009. 2010. http://www.midstaffsinquiry.com/documents.html laccessed 5 Aug 2011).

18. Dickinson C, Ham C. Engaging Doctors in Leadership: Review of the Literature. NHS Institute for Innovation and Improvement/Health Services Management Centre, Coventry, 2008.

19. Ham C, Alberti KGMM. The medical profession, the public, and the government. BMJ 2002:324:838-42.

20. Edwards N, Kornacki MJ, Silversin J. Unhappy doctors: what are the causes and what can be done? BMJ 2002;324:835-8.

21. Degeling $\mathbf{P}$, Maxwell S, Kennedy J, et al. Medicine, management, and modernisation: a "dance macabre"? BMJ 2003;326:649-52.

22. Russell V, Wyness LA, McAuliffe $E$, et al. The social identity of hospital consultants as managers. J Health Organ Manag 2010;24:220-36.

23. Abernethy MA, Stoelwinder JU. The role of professional control in the management of complex organizations. Account Organ Soc 1995;20:1-17.

24. Field A. Discovering Statistics Using SPSS. 3rd edn. London: Sage, 2009 
25. MacCallum RC, Widaman KF, Zhang S, et al. Sample size in factor analysis. Psychol Methods 1999;4:84-99.

26. Teunissen PW, Westerman M. Opportunity or threat: the ambiguity of the consequences of transitions in medical education. Med Educ 2011;45:51-9.

27. Busari J0, Berkenbosch L, Brouns JW. Physicians as managers of health care delivery and the implications for postgraduate medical training: a literature review. Teach Learn Med 2011;23:186-96.

28. HMSO. Health And Social Care Act. http://services.parliament.uk/bills/2010-11/ healthandsocialcare.html laccessed 13 Apr 2012).

29. General Medical Council. Good Medical Practice. 2006. http://www.gmc-uk.org/ guidance/good medical_practice.asp (accessed 2 Jun 2011).

30. General Medical Council. Good Management Practice: Guidance For All Doctors. 2011. http://www.gmc-uk.org/guidance/news_consultation/8851.asp laccessed 13 Apr 2012).
31. General Medical Council. Leadership And Management For All Doctors. 2012. http:// www.gmc-uk.org/guidance/ethical_guidance/11788.asp (accessed 25 May 2012).

32. Ham C, Dickinson H. Engaging doctors in leadership: what can we learn from international experience and research evidence? NHS Institute for Innovation and Improvement/Health Services Management Centre, Coventry, 2008.

33. Irby DM, Cooke M, O'Brien BC. Calls for Reform of medical education by the Carnegie Foundation for the advancement of teaching: 1910 and 2010. Acad Med 2010;85:220-7.

34. NHS Institute for Innovation and Improvement and Academy of Royal Colleges. Medical Leadership Competency Framework. Enhancing engagement in medical leadership. 3rd edn. Coventry: NHS Institute for Innovation and Improvement, University of Warwick, 2010. http://www.institute.nhs.uk assessment_tool/general/medical_leadership_competency_framework_homepage. $\bar{h}$ tml (accessed 13 Apr 2012). 